\title{
A CONTINUIDADE EDUCATIVA FRENTE A "QUARENTENA"
} EDUCATIONAL CONTINUITY FRONT OF THE "QUARANTINE”

\author{
Fabricia Sônego ${ }^{2}$
}

\section{RESUMO}

Este texto traz uma reflexão acerca da situação vivida por professores e alunos em virtude da crise decorrente da pandemia Covid-19, a qual instaurou o período chamado de "quarentena" em toda sociedade. Na esfera educacional, inúmeras alternativas de enfrentamento a essa situação de distanciamento social, foram vivenciadas. Com as escolas fechadas em grande parte do mundo, tornou-se inerente ao momento discussões sobre como proceder para que a continuidade educativa fosse mantida. Nesse sentido percebeu-se a necessidade de alternativas com o intuito de minimizar as desigualdades deflagradas durante o período de quarentena na esfera educacional, bem como a reflexão sobre a situação pós-crise.

Palavras-chave: Atividades escolares remotas, Pandemia Covid-19, Perspectivas educacionais.

\section{ABSTRACT}

This text reflects on the situation experienced by teachers and students due to the crisis arising from the Covid-19 pandemic, which established the period called "quarantine" in the entire society. In the educational sphere, numerous alternatives for coping with this situation of social distance were experienced. With schools closed in much of the world, discussions on how to proceed in order to maintain educational continuity became inherent at the time. In this sense, the need for alternatives was perceived in order to minimize the inequalities triggered during the quarantine period in the educational sphere, as well as the reflection on the post crisis situation.

Keywords: Remote school activities; Covid-19 Pandemic; Educational perspectives.

\footnotetext{
${ }^{1}$ Ensaio sobre a educação no contexto atual.

${ }^{2}$ Mestre em Políticas Públicas e Gestão Educacional. Docente do Instituto Federal Farroupilha. E-mail: fabriciasonego@ gmail.com
} 


\section{COMEÇANDO A CONVERSA...}

$\mathrm{O}$ ano de dois mil e vinte iniciou como todos os anos, anunciando um novo momento na vida de cada um. Esse novo momento, parte do conhecimento de senso comum de que a virada de ano notoriamente traz consigo a ideia de renovação.

Porém desde o início do ano, diferentes canais de comunicação e informação, noticiaram especulações acerca de um vírus, descoberto na China, com alta transmissibilidade e que em alguns casos, podia levar a morte seus infectados. Passados poucos dias dessas especulações a Organização Mundial da Saúde (OMS, 2020) alertou sobre a presença do "coronavírus", um vírus que desencadeava sintomas semelhantes aos de um resfriado mas que podia acarretar inúmeras complicações na saúde das pessoas, e que tinha possibilidade de transmissão para diferentes regiões do mundo devido a já citada, alta transmissividade. Esse fato comprovou-se, uma vez que pouco mais de trinta dias após o anúncio da "descoberta" do vírus, o mesmo já estava presente em diversos países do mundo, dentre eles o Brasil. A transmissão comunitária desse foi rapidamente percebida entre as pessoas.

A partir disso, medidas de contenção a propagação do vírus, bem como a ampliação do número de leitos, nas redes de saúde pública, para atender os doentes de Covid-19, foram ações tomadas pelos governantes a fim de evitar a contaminação generalizada pelo vírus. Em meio às medidas tomadas pelos estados e municípios, a efetivação do isolamento social foi fortemente indicada, originando o período chamado de quarentena.

Diante deste cenário, este ensaio apresenta uma reflexão, por meio da observação da situação vivida, nesse momento de tamanha insegurança em todos os setores e em especial na esfera educacional. Refletir sobre os acontecimentos e sobre como professores, alunos e famílias vem enfrentando esse momento atípico é inerente para a tomada de decisões e para orientação às medidas de continuidade educativa, tão necessárias nessa situação.

A ideia de continuidade educativa, como nos destaca Nóvoa (2000) é de que possamos vivenciar a situação de quarentena, sem esquecer que a relação entre alunos e professores precisa manter um vínculo. Esse vínculo perpassa as questões enfrentadas por todos os seres humanos nesse momento atípico que estamos vivendo e faz com que as relações entre ambos estejam permeadas pela empatia, por colocar-se no lugar do outro.

Neste ensaio, refletimos sobre como oportunizar a continuidade educativa aos alunos neste momento em que alunos e professores se encontram sem saber como agir. Um momento em que questões referentes à desigualdade sociais afloraram; a ampliação do acesso às ferramentas de informação e de comunicação tornaram-se essenciais; bem como a perspectiva de uma nova educação marcada 
pelas dificuldades vividas e pelas superações realizadas de diferentes maneiras pelas escolas, gestores e acima de tudo, pelos professores.

Assim, buscamos com este texto discutir, sobretudo a continuidade educativa, para todos os alunos que se encontram afastados da escola, isolados do convivo escolar, mas que mesmo assim vivenciam inúmeras aprendizagens para além dos conteúdos científicos, mas essencialmente aprendizagens de vida em comunidade. E a vida em comunidade de hoje, nos mostra que a reinvenção é inerente a todos nós e o professor como ser humano, precisa pensar em como propor estratégias para a continuidade educativa a partir da sua humana docência, como nos aponta Arroyo (2000), sobre a capacidade do professor de compreender o outro.

Mesmo distantes, "presos em quarentena”, nós professores, precisamos pensar juntos maneiras de "encontrar" nossos alunos, propormos atividades com conteúdos escolares, mas acima de tudo ouvir, compreender e valorizar o que é vivido, percebido e aprendido em meio a essa situação, por alunos, professores e famílias.

\section{MATERIAL E MÉTODOS}

A situação estabelecida no período de isolamento social proveniente da disseminação do corona vírus, trouxe incertezas para o cenário educacional como comentado até este momento. Em vista disso é inerente pensarmos no problema gerado em virtude disso, e nos questionarmos sobre como a esfera educacional foi afetada em meio à pandemia Covid-19.

Essa questão deu origem aos propósitos apresentados neste ensaio. Entre esses, estão a reflexão sobre a esfera educacional, trazida por alguns autores que ousaram propor estratégias de enfrentamento ao problema. As ideias desses foram contextualizadas a fim de elaborar este texto que pretende refletir e a partir daí fortalecer a ideia de continuidade educativa durante e após o período de crise.

A natureza deste ensaio parte de uma abordagem qualitativa pois pretende refletir acerca das situações educacionais, bem como o impacto dessas nas escolas. Conforme Lankshear e Knobel (2008, p.66) “os pesquisadores qualitativos visam coletar dados que sejam contextualizados". Assim, este ensaio foi organizado a partir da observação da situação sócio-histórico-cultural vivida em meio à quarentena, baseado na investigação sobre o contexto real bem como a ênfase na interpretação e na dedução dos significados das vivências desse período (LANKSHEAR, KNOBEL:2008).

Temos certeza de que as reflexões aqui trazidas não se esgotam neste texto. São apenas propulsoras de discussões sobre a situação vivida na esfera educacional em nosso país e também no mundo. A tomada de decisões nesse momento precisa levar em conta vários aspectos comentados nesse ensaio e inúmeros outros, a serem discutidos incansavelmente, visto que este assunto tem grande impacto na vida escolar de milhares de estudantes em todo mundo. 
A ESFERA EDUCACIONAL, AÇÕES E IMPACTOS.

O início do ano de dois mil e vinte foi marcado por uma situação inusitada em todo o mundo. No Brasil, em meados o mês de março, com a instauração da pandemia mundial Covid-19, originada pelo surgimento de um novo vírus de alta transmissão e com diagnósticos de letalidade em alguns casos, trouxe a toda população um cenário extremamente atípico.

Em virtude disso, medidas de prevenção foram indicadas pela Organização Mundial de Saúde (OMS) e pelos governos federais, estaduais e municipais de diferentes partes do mundo. Inúmeros setores da economia, envolvendo indústria, comércio e lazer tiveram que se adaptar aos protocolos de contenção e proteção ao corona vírus. Tal período denominado de "quarentena" perdurou por mais que quarenta dias. Foi prolongando-se à medida que os dados fornecidos pela OMS, bem como as medidas organizadas pelas entidades federativas tiveram continuidade devido ao aumento significativo de casos de Covid-19 em todo território nacional (Lei federal $\mathrm{n}^{\mathrm{o}} 13.979$, de 06 de fevereiro de 2020).

Em meio aos setores impactados com as medidas previstas na quarentena objetivando a proteção e a contenção da propagação do vírus supracitado, as quais incluíram a efetivação de trabalho remoto $^{3}$, famílias trabalhando em home office 4 e cuidando de seus escolares em casa, fechamento total ou parcial de estabelecimentos e de atividades que geravam aglomerações de pessoas, as escolas também foram fechadas e as atividades escolares suspensas a fim de se incorporar o período de isolamento social. As aulas em muitos casos foram suspensas totalmente num primeiro momento ou passaram a ser realizadas em casa, junto das famílias, que por sua vez (e na medida do possível), também estavam em casa nesse período (Decreto estadual n $n^{\circ} 55.118$, de 16 de março de 2020, Portaria federal no 343 , de 17 de março de 2020).

Esse movimento deveria durar o tempo necessário para que o distanciamento social diminuísse a propagação do vírus e os setores de saúde pudessem instrumentalizar-se a fim de conseguir atender a população com sintomas mais graves. Esse período foi marcado por um cenário social e econômico conturbado e as vivências das famílias em vista disso também foram fortemente afetadas.

Diante da situação de crise na saúde mundial, e com as escolas fechando suas portas a fim de seguir protocolos de proteção insaturados em todas as unidades federativas, um longo período de incertezas permeou o cenário educacional. Esse período gerou diferentes percepções pelos professores que trabalharam disponibilizando atividades para seus alunos, e pelas famílias, que pela primeira vez viram-se impostas a realizar essa tarefa, antes designada apenas à escola, e vivida em família por meio dos "temas de casa". Um número enorme de estudantes passou a ficar em suas residências,

\footnotetext{
${ }^{3}$ Trabalho remoto ou atividades remotas referem-se à utilização de recursos tecnológicos complementares ao ensino e aprendizagem utilizado em caráter emergencial.

${ }^{4}$ Home Office refere-se ao trabalho desenvolvido pelo funcionário da própria residência por meio ferramentas digitais interligadas, oportunizando o trabalho em rede.
} 
assim como professores, sem saber ao certo o que fazer. Professores e alunos se depararam com uma situação inusitada, na qual tiveram que se reinventar.

A situação disparou o medo entre as pessoas e o contato físico passou a ser repelido. Em meio a essas e muitas outras sensações, constituiu-se a quarentena.

A relação entre o ser humano e o mundo permeou-se de desafios, incertezas e inseguranças. Porém, como nos destaca Freire, o ser humano tem como característica humana responder as situações que o desafiam, é intrínseco aos homens o ato de buscar soluções, buscar formas de responder as dificuldades que a si são apresentadas. Conforme o autor,

\begin{abstract}
Há uma pluralidade nas relações do homem com o mundo, na medida em que responde à ampla variedade dos seus desafios. Em que não se esgota num tipo padronizado de resposta. A sua pluralidade não é só em face dos diferentes desafios que partem do seu contexto, mas em face de um mesmo desafio. No jogo constante de suas respostas, altera-se no próprio ato de responder. Organiza-se. Escolhe a melhor resposta. Testa-se. Age. Faz tudo isso com a certeza de quem usa uma ferramenta, com a consciência de quem está diante de algo que o desafia. (FREIRE, 1967, p. 40-41)
\end{abstract}

Passados dias, semanas, meses de quarentena, viu-se a necessidade de responder a esse desafio, de buscar organizar-se diante da situação e escolher respostas, viu-se a necessidade urgente da tomada de decisões sobre como conduzir tal situação educacional. De um lado, estavam os profissionais a favor da continuidade das atividades escolares por meio de instrumentos on-line, e de outro lado, os indicadores de uma falsa "ampla continuidade escolar", que devido às diferenças gritantes da distribuição de renda em nosso país, aguçou as segregações entre a população escolar. Escolas particulares mantendo suas atividades a distancia e escolas públicas, sobretudo de periferia, tentando sobreviver em meio à incerteza “do que fazer?”...

Num país com uma enorme disparidade na distribuição de renda é visível que grande parte da população escolar não tenha acesso ao mundo digital, mascara-se esse acesso ao mundo digital por meio de um plano de dados móveis que possibilita pouco mais que entretenimento fugaz. O julgado mundo digital cai por terra uma vez que as escolas, professores e alunos se mostram desconexos nessa interatividade. O mundo que era dito como digital, on-line e conectado mostra-se cada vez mais analógico, sem conhecimento acerca das tecnologias da comunicação e da informação, com medo, com fome, perdido...

A incerteza do tempo vivido e o temor tomam conta das pessoas que devido aos movimentos em prol da quarentena, deparam-se com um momento de solidão e reclusão, essa, permitida apenas aos que tinham condições de usufruí-la, uma vez que puderam manter-se afastados uns dos outros sem falta de nenhum bem necessário ao dia a dia como alimento, conforto, contas pagas e a escola em frente ao computador. Cenário disforme, uma vez que dados do Instituto Brasileiro de Geografia e Estatística (IBGE), de 2018, mostram que apenas 1\% da população mais rica possui o rendimento mensal de R \$ 27. 744,00, enquanto 50\% da população mais pobre vive com R \$ 820,00 por mês. Esse dado corrobora o fato de que a população brasileira é marcada por uma grande diversidade social e 
econômica que acarreta enorme desigualdade e por isso situações divergentes em relação ao acesso e as possibilidades do mundo digital, que nesse momento surgem como alternativa de continuidade da escola em meio à quarentena.

Porém o momento exige urgência e o mundo das coisas ${ }^{5}$ precisa ser vivido não apenas por uma parcela da população, que em uma sociedade historicamente capitalista, separa os que têm acesso as facilidades que o mundo em rede oportuniza daqueles que vivem a margem dessa realidade. Iludidos por uma suposta interação no mundo digital baseada em redes de relacionamento.

Diante disso nos deparamos com o questionamento sobre como propiciar a continuidade educativa nesse cenário. Como já mencionamos neste texto, Freire (1967) já nos apontava que a relação entre o homem e o mundo partia da interação com os desafios apresentados pelo mundo e pelas respostas, tentativas, maneiras de organizar-se a estes. Por isso a necessidade de nos questionarmos sobre como manter o vínculo entre professores e alunos. O desafio atual é como reagirmos a esse cenário de quarentena. Como nos organizarmos para agir nesse momento.

É certo que precisamos definir objetivos educacionais para esse período, a fim de orientar as ações. A escuta pelas secretarias de educação, de seus gestores, professores e comunidades escolares a fim de juntos definirem uma estratégia é uma ação necessária. A situação é nova para todos os envolvidos e cada um desses apresenta suas limitações diante da situação de crise, por isso a escuta de todos "os lados da escola" é necessária. As questões vividas, os saberes de cada território educativo, a busca ativa pelos estudantes, são ações que precisam permear esse momento de produção de estratégias no campo educacional.

Algo precisa ser feito. O mundo para, mas a capacidade do ser humano em ser reinventar e de procurar alternativas de como fazer em meio a esse cenário não pode parar. Além disso, como nos afirma Nóvoa (2020), frente a esta situação, dada como pandemia, não é possível não fazer nada. Precisamos fazer alguma coisa por nossas escolas e por nossos alunos. É preciso agir para manter a continuidade educativa, a continuidade escolar. A situação que nos deparamos é sem dúvidas, difícil, mas é necessário sermos reativos, é necessário reagirmos a essa situação e não ficarmos estagnados esperando que tudo passe. É momento de colocarmos nossas competências, nossos saberes e nossos conhecimentos a serviço da continuidade educativa (NÓVOA e MOTA, 2020).

Diante de um cenário de escolas fechadas, reinventar a profissão docente torna-se inerente a esse momento. Sem nunca esquecer que o professor é um ser humano que foi apunhalado pela situação de calamidade proveniente da pandemia. Se viu perdido em meio a quarentena, situação normal dentro de tamanha anormalidade.

O professor, como todas as pessoas, também não sabe como agir. É um ser humano tentando ser o mais humano possível, consigo e com o outro. Esse deve ser o sentido prevalente. Falamos de

\footnotetext{
${ }^{5}$ Fazendo referencia nesse momento a Internet das Coisas e a ideia trazida com essa, de cada vez mais interligar o mundo físico ao mundo digital.
} 
uma profissão que mais do que nunca precisa estar permeada pelo sentimento humano. E é por isso que a ideia da humana docência, destacada por Arroyo, que precisa alicerçar a reinvenção dos professores nesse momento.

\begin{abstract}
"Sermos obrigados a ver as crianças e os adolescentes, os jovens e adultos com que se convive nas salas de aula como humanos plenos, em processos de formação na totalidade de potencionalidades humanas e em formas de viver tão precarizadas, assumir essa complexa tarefa como um trabalho profissional terminará por alargar o projeto de realização profissional e humana a que todo docente tem direito como ser humano pleno que é. [...] Em outros termos: aprender com os educandos a sermos educadores amplia e enriquece nosso projeto de realização profissional e humana. O professor é um ser humano, sua docência é humana docência com tudo que implica escolha, de realização humana (ARROYO, 2011, p. 26)
\end{abstract}

E é nessa realização profissional que surge o professor capaz que definir o que importa nesse momento para si e para seus alunos. O professor que conhece os alunos, sabe de onde esses partem, tem condições de organizar uma estratégia de continuidade educativa que leve em conta os seres humanos que estão envolvidos. Mais do que nunca o ser humano precisa ser levado em consideração e ser o ponto central de toda discussão sobre como a escola irá superar esse momento de isolamento social, mantendo laços e alargando os vínculos entre alunos e professores.

Segundo as considerações de Nóvoa (2020), a história mostra que quando se interrompe o percurso escolar do aluno mais frágil, pode significar que ele não retorne a escola, pode significar que seu percurso escolar está sendo interrompido permanentemente. Por isso ressaltamos a importante necessidade docente de reinventar os métodos de trabalhos frente à pandemia e agir a favor dos estudantes, pois esses não estão inertes a tudo isso, eles seguem construindo seu desenvolvimento. Conforme Leite (2020), mesmo em casa os alunos seguem construindo sua bagagem de aprendizagens, em meio a essa situação. Assim temos que pensar a questão das escolas fechadas a partir da ideia de um ciclo de aprendizagens. Não temos como discutir nesse momento somente como será a recuperação dos dias letivos, mas sim, as condições de vida e de aprendizagem que estão ocorrendo nesse momento, precisamos entender esse tempo e transformá-lo em saberes.

É preciso que nossos objetivos para este momento levem em conta essas especificidades dos alunos, além das dos próprios professores. Assumir que o medo interfere em nossas tomadas de decisão é saber que essas requerem reflexão, requerem aproximação com os envolvidos com a escola. Podemos aproximar essa reflexão do que nos traz Freire sobre a necessidade de reconhecer o medo e não fazer com esse impeça nossas ações.

Há sempre uma relação entre medo e dificuldade, medo e difícil. Mas, nesta relação, obviamente, se acha também a figura do sujeito que tem medo do difícil ou da dificuldade. [...] A questão que se coloca não é, de um lado, negar o medo, mesmo quando o perigo que o gera é fictício. O medo, porém, em si é correto. A questão que se apresenta é não permitir que o medo facilmente nos paralise. (FREIRE, 1993, p. 39). 
Em nosso contexto, o perigo que gera o medo não é fictício. Mesmo assim, podemos perceber que estar com medo da situação vivida é normal ao ser humano e como um ser humano, aos professores. Porém precisamos escolher entre fazer alguma coisa ou fechar-se em quarentena. Sendo a primeira opção, inerente a continuidade educativa daqueles que esperam de nós, professores, ajuda para compreender e para viver a situação tão difícil deste momento.

É preciso assegurar a continuidade educativa e por isso fechar-se em quarentena sem pensar essas questões é assumir uma posição egoísta que não condiz com o perfil profissional do professor, como nos destaca fortemente Nóvoa (2020), não fazer nada não é o caminho.

Precisamos reconhecer que não sabemos o que e como fazer, mas que precisamos fazer, precisamos reagir a esse momento para que inúmeras vidas escolares não sejam ceifadas por uma quarentena que pretende proteger de um inimigo invisível mas que mascara outros inimigos bem mais aparentes mas que nesse cenário de medo que uma pandemia sugere, ficam obscuros e aguçam as desigualdades em todos os setores.

Mesmo assim, sabemos que fazer alguma coisa não é fácil uma vez que a quarentena está instaurada em todo território nacional, as escolas estão fechadas e inúmeras outras medidas de contenção a propagação da contaminação do corona vírus estão vigorando, e aqui não discutimos a legitimidade dessas medidas, uma vez que são necessárias ao momento vivido, porém não podemos ser ingênuos e não ver que essas medidas enfraquecem possíveis ações em prol da continuidade educativa, mas que em momento algum impedem com que essas sejam pensadas e propostas.

Diante disso, precisamos estar cientes de que o uso das ferramentas digitais são alternativas de enfrentamento ao momento vivido, não são a solução para um problema que não terá uma solução única, terá medidas de enfrentamento e adaptação frente às condições de proteção ao vírus. Propostas de atividades remotas, atividades à distância ${ }^{6}$, atividades domiciliares ${ }^{7}$, atividades por meio de contatos em redes sociais, atividades entregues em datas acertadas pelas escolas e também atividades entregues aos alunos em casa foram e são alternativas realizadas a fim de continuar o vínculo escolar, são formas de proporcionar a continuidade educativa. Conteúdos novos ou meros exercícios, atividades, leituras, filmes... São várias as fontes utilizadas como meio de fazer o professor presente dentro das casas.

Porém não podemos esquecer que muitos alunos, fora da escola, não tem condições adequadas para realização dessas tarefas. Aqui não estamos indicando a falta de acesso a internet, visto que existem maneiras de entregar atividades impressas aos alunos e mesmo assim, esses não tem condições

\footnotetext{
6 A atividade a distância citada aqui se refere as atividades organizadas pelos professores durante o período de quarentena e disponibilizadas aos alunos por ferramentas digitais (e-mail, whatssap, Google classroom, Google meet, entre outros). Destacamos que o termo usado difere da nomenclatura "educação à distância - EAD", visto que essa é regulamentada como modalidade de ensino segundo a Lei de Diretrizes e Bases da Educação (LDB 9394/96) tendo organização específica para desenvolver-se dessa maneira. Porém o termo EAD vem sendo utilizado seguidamente por senso comum, nesse momento de pandemia, sem a devida diferenciação.

7 Atividades domiciliares também chamadas de "homescholling" fazem parte de um movimento que visa conferir unicamente às famílias a educação de crianças e adolescentes, atividade que não possui amparo legal no Brasil.
} 
de realiza-las por diversos motivos. Entre esses motivos estão situações comuns percebidas pelos próprios professores, que interferem na realização de tarefas de casa, como: existência de moradias em que os quartos são compartilhados; existência de apenas uma mesa na casa; o número de familiares na mesma residência impede que haja um ambiente calmo para realização das atividades; familiares com dificuldades de leitura e escrita para auxiliar nas atividades; escassez de alimentos; entre muitas outras condições de infraestrutura, bem como questões organizacionais das famílias.

Essas situações, em que vivem as famílias, ficaram evidentes durante o período da quarentena. Como já destacamos, não falamos aqui só do aluno que não tem acesso à internet ou as atividades que não recebe ou que recebe mas não sabe como fazer. Mencionamos aqui o que Santos (2020) chama de "sul” da quarentena. Famílias inteiras foram discriminadas nesse período que fingiu resguardar todas as pessoas. Os mais vulneráveis tiveram que decidir entre fazer parte do movimento de frenagem do vírus ou seguir seu movimento de sobrevivência. Santos (2020) ainda destaca que inúmeros grupos da sociedade sobrevivem de atividades informais e por isso permanecer em casa, em quarentena a fim de proteger-se do vírus, seria uma ótima solução, se esses grupos não dependessem do trabalho diário para garantir recursos e assegurar alimento e a própria segurança para suas famílias, assim tiveram de decidir entre morrer do vírus ou morrer de fome. Podemos estar grosseiramente reforçando essa situação, mas a necessidade do trabalho informal esta presente em muitas famílias em todos os lugares e com a quarentena, esse trabalho que muitas vezes depende dos consumidores da rua foi bruscamente diminuído.

Além desse grupo, Santos (2020) destaca vários outros que foram sacrificados nesse período de suposta proteção, instaurado pela quarentena, como os trabalhadores da saúde que fizeram a linha de frente na pandemia, e as mulheres que conciliaram as atividades domésticas com o trabalhos realizados de casa nesse período. Sem contar os grupos que vivem em “quarentena”, alheios às famílias ou a própria sociedade e que nesse momento viram-se na quarentena dentro da quarentena como os moradores das casas de idosos, os moradores de rua, as pessoas com necessidades especiais (SANTOS, 2020).

Essa realidade, como nos salienta Santos (2020), mostra que a quarentena tornou visível o que não podia ser visto, os altos níveis de injustiça social, a discriminação, a exclusão social dentro de uma sociedade que se uniu a fim de proteger-se contra um inimigo invisível, que gerou um sentimento de ajuda mútua no mundo inteiro e que fez aparecer o que já existia e que comovia a poucos... infelizmente. A cruel situação pandêmica fez surgir sentimentos de empatia que nunca deveriam ter sido esquecidos pois antes do vírus, outras "pandemias” permearam nosso mundo.

\section{E O PÓS-CRISE?}

E depois de tudo isso, nos questionamos, haverá normalidade após a crise? É certo que novos tempos virão, porém essa compreensão é determinada pelos sujeitos que viverão o pós-crise e como esses viverão. É necessário que a população se aproprie de inúmeras medidas benéficas tomadas 
durante esse período e passe a realiza-las cotidianamente. Essas vão além das medidas de higiene e saúde, agregam condições de relacionamento humano que perpassam pelo trabalho colaborativo, pela empatia, pela utilização de tecnologias de informação e de comunicação em favor do ser humano.

O mundo pós-crise precisa ser um mundo sensível às injustiças e as diferenças evidenciadas durante os meses de quarentena. Precisa perceber que as desigualdades sociais não fazem parte da normalidade de nosso planeta e que precisam ser vistas como um desafio a todos nós. Freire (1967) nos deixa claro que os desafios servem para nos impulsionarmos na busca de soluções, de respostas, de maneiras para tentar, para agir a fim de enfrentar nossos problemas.

Nossas tentativas precisam ser constantes, afim de que esse momento que vivemos não entre pra história sem deixar mudanças nas pessoas. Sem fazer com que essas se tornem mais humanas com o outro e com o mundo que nos cerca. A vida em comunidade foi castrada durante o período de pandemia, o isolamento social e a orientação para permanecer em casa durante a quarentena fizeram com que pessoas e espaços fossem valorizados e esse sentimento precisa ser um marco na trajetória da humanidade.

Santos (2020) e Nóvoa (2020) indicam que o mundo não pode mais sobreviver à humanidade que não compreende que além dos seres humanos inúmeros outros ecossistemas constituem nosso planeta. Por isso, o pós-crise é saber que precisamos viver em sintonia uns com os outros, como nos destaca Nóvoa (2020), o mundo não pode seguir como está, no pós-crise passaremos por uma transição ecológica a fim de respeitar a natureza como fundamental para nossa existência no planeta terra.

Além disso, a situação pós-pandemia produzirá a transição digital uma vez que a quarenta obrigou-nos a nos relacionar efetivamente por meio de ferramentas digitais. Tanto as relações entre as famílias como as relações comerciais foram intensificadas pelos meios digitais. Nunca houve tantas atualizações nas ferramentas tecnológicas e novas ideias a fim de possibilitar reuniões sem aglomerações de pessoas, atividades comerciais on-line, atendimento digital, atividades escolares por meio de ferramentas síncronas e assíncronas, e a tentativa de realização de diferentes tarefas cotidianas por meio dos aplicativos de celulares. Podemos inferir que nunca em tão pouco tempo, as ferramentas da tecnologia da comunicação e da informação foram tão difundidas, utilizadas, pensadas e otimizadas.

Essas, além de possibilitar as relações de trabalho e as relações comerciais, possibilitaram também a "presença distante" das pessoas. Não podemos deixar de destacar a importância que as ferramentas digitais tiveram durante o período de pandemia em relação ao vínculo entre as famílias, amigos, colegas e claro, alunos e professores.

O uso das tecnologias nesse cenário pandêmico demonstrou a importância dessas ferramentas no contexto mundial, em que a imersão nessas ferramentas que possivelmente levaria anos para se difundir como se difundiu, ocorreu em um curto espaço de tempo, por meio de experimentações, tentativas de erro e acerto. Esse movimento demonstrou a capacidade docente de reagir frente aos desafios.

E é também por isso, que a crise nos oportunizará a transição escolar. Há um novo modelo de escola surgindo, capaz de se integrar ao contexto atual. Como nos destaca Freire (1967), integrar-se 
a uma situação é ser sujeito dessa situação, diferentemente de como agimos no início da pandemia, adaptando-nos como seres passivos aquela situação atípica e inusitada.

Uma metamorfose da escola, com novos ambientes de aprendizagem, novos espaços educativos. Uma escola que emerge rumo à educação integral em todos os tempos e espaços. Uma escola em que o professor ocupará de fato um lugar de mediador, de pesquisador, de possibilitador. Uma escola cuja reinvenção do trabalho pedagógico e do trabalho educativo é inerente.

Segundo Nóvoa (2020), o contexto vivido não vai mudar a história, a crise vai acelerar a transição ecológica, a transição digital e a transição escolar por meio da cooperação. Vai oportunizar a metamorfose da escola, dando lugar a uma nova educação.

A sociedade vai se adaptar a esse novo modelo, a esse novo modo de viver. Passará por uma metamorfose que partiu da "normalidade", viveu o período imprevisível da crise Covid-19, até chegar a uma nova "suposta normalidade" dentro de um "novo mundo" em que estamos adentrando. Uma sociedade mais humana, capaz de ver o que não é visto, compreender o que não é compreendido e acima de tudo capaz de cooperar com o outro e com o nosso planeta.

\section{REFERÊNCIAS}

ARROYO, Miguel. Ofício de mestre: Imagens e auto-imagens. Petrópolis: Vozes, 2000.

Currículo, território em disputa. Rio de Janeiro: Vozes, 2011.

BRASIL. Lei $\mathbf{n}^{\mathbf{0}}$ 13.979, de 06 de fevereiro de 2020. Dispõe sobre as medidas para enfrentamento da emergência de saúde pública de importância internacional decorrente do coronavírus responsável pelo surto de 2019. Disponível em: https://bit.ly/32kLkCN. Acesso em: 10 de maio de 2020.

Portaria no 343, de 17 de março de 2020. Dispõe sobre a substituição das aulas presenciais por aulas em meios digitais enquanto durar a situação de pandemia do Novo Coronavírus - COVID-19. Disponível em: https://bit.ly/36eSnxV. Acesso em: 10 de maio de 2020.

ÍNDICE BRASILEIRO DE GEOGRAFIA E ESTATÍSTICA (IBGE). Disponível em: https:// www.ibge.gov.br/. Acesso: 01 de junho de 2020.

FREIRE, Paulo. Educação como prática da liberdade. Rio de Janeiro: Editora Paz e Terra, 1967. . Professora sim tia não: cartas a quem ousa ensinar. 19. Ed. São Paulo: Olho d’Água, 1993. 
LANKSHEAR, Colin. KNOBEL, Michele. Pesquisa pedagógica: do projeto à implementação. Tradução Magda França Lopes. Porto Alegre: Artmed, 2008.

LEITE, Lúcia Helena Alvarez. Escolas fechadas, e agora? (vídeo/YouTube) Grupo TEIA - Territórios, Educação Integral e Cidadania - FAE/UFMG. Disponível em: https://youtu.be/wG14wXawqgY. Acesso em: 01 de junho de 2020.

NÓVOA, Antônio. Formação Continuada Territorial a Distância. (Live/YouTube). Secretaria da Educação do Estado da Bahia. You Tube. Disponível em: https://youtu.be/7kSPWa5Nie. Acesso em: 01 de junho de 2020 .

NÓVOA, Antônio. MOTA, Ronaldo. Docência em tempos de pandemia. (webconferência). UFSM. Repositório Farol.UFSM.BR. Disponível em: https://bit.ly/2TY83Qi. Acesso em: 01 de junho de 2020.

Organização Mundial de Saúde (OMS). World Health Organization, 2020. Coronavírus. Disponível em: https://bit.ly/2Icrl27. Acesso em: 10 de maio de 2020.

RIO GRANDE DO SUL. Governo do Estado do Rio Grande do Sul. Decreto $\mathbf{n}^{\mathbf{0}} \mathbf{5 5 . 1 1 8}$, de 16 de março de 2020. Estabelece medidas complementares de prevenção ao contágio pelo COVID-19 (novo Coronavírus) no âmbito do Estado. Disponível em: https://educacao.rs.gov.br/. Acesso em: 27 de abril de 2020 .

SANTOS, Boaventura de Sousa. A cruel pedagogia do vírus. Coimbra, PT: Edições Almedina, S.A, 2020. 